\title{
GMR
}

\section{Methylation-sensitive amplified polymorphism- based genome-wide analysis of cytosine methylation profiles in Nicotiana tabacum cultivars}

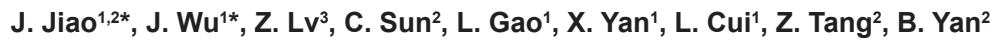 \\ and $\mathrm{Y} . \mathrm{Jia}^{4}$ \\ ${ }^{1}$ School of Basic Medicine, Xinxiang Medical University, Xinxiang, Henan, China \\ ${ }^{2}$ Agronomic College, Sichuan Agriculture University, Ya'an, Sichuan, China \\ ${ }^{3}$ The Third Affiliated Hospital of Xinxiang Medical University, Xinxiang, Henan, China \\ ${ }^{4}$ Pharmacy College, Xinxiang Medical University, Xinxiang, Henan, China \\ *These authors contributed equally to this study. \\ Corresponding author: Y. Jia \\ E-mail: yljiacn@126.com \\ Genet. Mol. Res. 14 (4): 15177-15187 (2015) \\ Received April 7, 2015 \\ Accepted July 31, 2015 \\ Published November 25, 2015 \\ DOI http://dx.doi.org/10.4238/2015.November.25.6
}

\begin{abstract}
This study aimed to investigate cytosine methylation profiles in different tobacco (Nicotiana tabacum) cultivars grown in China. Methylationsensitive amplified polymorphism was used to analyze genome-wide global methylation profiles in four tobacco cultivars (Yunyan 85, NC89, K326, and Yunyan 87). Amplicons with methylated C motifs were cloned by reamplified polymerase chain reaction, sequenced, and analyzed. The results show that geographical location had a greater effect on methylation patterns in the tobacco genome than did sampling time. Analysis of the CG dinucleotide distribution in methylation-sensitive polymorphic restriction fragments suggested that a $\mathrm{CpG}$ dinucleotide cluster-enriched area is a possible site of cytosine methylation in the tobacco genome. The sequence alignments of the Nia1 gene (that encodes nitrate reductase) in Yunyan 87 in different regions indicate that a $\mathrm{C}$ - $\mathrm{T}$ transition might be responsible for the
\end{abstract}


tobacco phenotype. T-C nucleotide replacement might also be responsible for the tobacco phenotype and may be influenced by geographical location.

Key words: Methylation-sensitive amplified polymorphism; Nia1; Epigenetics; Methylation; Tobacco (Nicotiana tabacum); Phenotype

\section{INTRODUCTION}

Epigenetics involves mechanisms that alter gene expression without changing DNA sequences, and can be inherited by mitosis or meiosis (Guimil and Dunand, 2006; Henderson and Jacobsen, 2007). DNA methylation is one of the most important processes in epigenetics, in addition to histone modifications and small regulatory RNAs. Methylation-sensitive amplified polymorphism (MSAP) has been widely used to study epigenetic information in plants (Noyer et al., 2005; Sha et al., 2005; Li et al., 2007), particularly in non-model species in which genome assembly information is not available. In the case of model organisms with genome assemblies, whole-genome bisulfite sequencing is the best option for reduced-representation libraries.

Amplified fragment length polymorphism (AFLP) is a molecular marker technique that can be combined with restriction fragment length polymorphism and polymerase chain reactions (PCRs) to analyze DNA (Vos et al., 1995). Two restriction endonucleases (EcoRI and Msel) are usually used in AFLP to slice the genome in order to form restriction endonuclease-sliced fragments with different ends. The technology has been widely used to analyze the relationships between germplasm resources in rice (Oryza, Chandel et al., 2010), cotton (Gossypium, Zhang et al., 2005), corn (Zea mays L., Frascaroli et al., 2013), barley (Hordeum brevisubulatum, Shan et al., 2012), peanuts (Arachis hypogaea, Jiang et al., 2007), rye (Secale cereale L., Falke et al., 2008), and tobacco (Nicotiana tabacum, Bahulikar et al., 2004). However, few studies have investigated the relationship between epigenetic factors, yield, and quality.

MSAP was first reported to be capable of detecting methylation differences in 1997 in dimorphic fungi (Reyna-López et al., 1997) and can detect polymorphisms based on the methylation status of whole genomes. MSAP has been successfully applied to study methylationbased polymorphisms in rice (Oryza, Xiong et al., 1999), pepper (Capsicum annuum, Portis et al., 2004), corn (Zea mays L., Zhao et al., 2007; Lu et al., 2008), tomato (Solanum lycopersicum, Mason et al., 2008), and banana (Musa x paradisiaca, Baurens et al., 2003). However, few studies have been conducted on C-methylation-based polymorphisms in tobacco.

In this study, MSAP was used to analyze epigenetic information, specifically cytosine methylation, in tobacco, including the extent, patterns, and site preferences of this process. Methylated polymorphic fragments were reamplified, and the characteristics of their distributions were analyzed to determine the potential predominance of $\mathrm{CpG}$ islands. The sequence characteristics of the Nia1 gene (that encodes nitrate reductase, NR) were also analyzed, and the possible effects of geographical factors on tobacco characteristics are discussed.

\section{MATERIAL AND METHODS}

\section{Plant materials}

Four tobacco cultivars were used: Yunyan 85, Yunyan 87, K326, and NC89. These cultivars were planted in Ya'an, Sichuan, China. Two other Yunyan 87 plants were planted in Yaojia and Xingwen, Sichuan, China. The leaves of all four tobacco cultivars were collected on July 14, 
2009. The leaves of three more Yunyan 87 plants used in the study were collected from Guanyuan, Luzhou, and Yibin in Sichuan, China on August 15, 2009 and August 15, 2010.

\section{DNA extraction}

Genomic DNA was isolated from leaf tissues according to Tang et al. (2008).

\section{AFLP and MSAP analysis}

The Msel, Hpall/Mspl, and EcoRI adaptors, pre-selective primers, and selective primer combinations are listed in Table 1 (Vos et al., 1995; Xiong et al., 1999). Repeats were conducted for the AFLP and MSAP procedures. The upper and lower parts of the AFLP and MSAP gels were not used for band scoring, because the bands were not satisfactory; only repeatable and stable patterns were used for the analysis. During the MSAP, bands of two parallel digestions for each sample $(E c o R I+H p a l l$ and $E c o R I+M s p l)$ were compared. The AFLP and MSAP procedures were performed according to Zhang et al. (2008).

\begin{tabular}{|c|c|}
\hline Primers & Sequnce \\
\hline \multicolumn{2}{|l|}{ Adaptors } \\
\hline EcoRI-adaptors-F & 5'-CTCGTAGACTGCGTACC-3' \\
\hline EcoRI-adaptors-R & 5'-AATTGGTACGCAGTC-3' \\
\hline Msel-adaptors-F & 5'-GACGATGAGTCCTGAG-3' \\
\hline Msel-adaptors-R & 5'-TACTCAGGACTCAT-3' \\
\hline Hpall/Mspl-adaptors-F & 5'-GATCATGAGTCCTGCT-3' \\
\hline Hpall/Mspl-adaptors-R & 5'-CGAGCAGGACTCATGA-3' \\
\hline \multicolumn{2}{|l|}{ Preselective primers } \\
\hline EcoR-A & 5'-GACTGCGTACCAATTCA-3' \\
\hline Mse-C & 5'-GACGATGAGTCCTGAGTAAC-3' \\
\hline Hpa/Msp-T & 5'-ATCATGAGTCCTGCTCGGT-3' \\
\hline \multicolumn{2}{|c|}{ Selective primer combinations used in AFLP } \\
\hline EcoRI-AAC + Msel-CAC & EcoRI-AAC + Msel-CTC \\
\hline EcoRI-AAC + Msel-CTG & EcoRI-AAG + Msel-CTA \\
\hline EcoRI-AAG + Msel-CTG & EcoRI-AAG + Msel-CAG \\
\hline EcoRI-AAG + Msel-CAC & EcoRI-ACA + Msel-CAG \\
\hline EcoRI-ACA + Msel-CTA & EcoRI-ACA + Msel-CTC \\
\hline \multicolumn{2}{|l|}{ EcoRI-ACA + Msel-CTG } \\
\hline \multicolumn{2}{|c|}{ Selective primer combinations used in MSAP } \\
\hline EcoRI-ACA + Hpall/Mspl-TCAA & EcoRI-AAC + Hpall/Mspl-TCTA \\
\hline EcoRI-AAC + Hpall/Mspl-TCTC & EcoRI-AAC + Hpall/Mspl-TCTG \\
\hline EcoRI-AAC + Hpall/Mspl-TCTT & EcoRI-AAG + Hpall/Mspl-TCAA \\
\hline EcoRI-AAG + Hpall/Mspl-TCTA & EcoRI-ACA + Hpall/Mspl-TCTA \\
\hline
\end{tabular}

Bold letters indicate selective nucleotides.

\section{Isolation and sequencing of polymorphic methylated fragments}

The polymorphic MSAP amplicons were sliced from polyacrylamide gels using blades, reamplified by PCR, and sequenced. The procedures were performed according to Tang et al. (2008).

\section{Isolation of the NR gene, ornithine decarboxylase, and ribulose decarboxylase}

Five primers pairs were designed according to the sequence for amplifying the NR gene, 
based on the genome sequence of Nia1 (GenBank accession No. X14058.1) and the role of the NR gene in quality differences between different tobacco cultivars; they were Nia1-1 (5'-TACTGG TGTTGGTGCTTTTGGTC-3', 5'-TCAGGGGAGATGGATTGTTTGTC-3'), Nia1-2 (5'-GCCACTCCT CCGAAAATAAAT-3', 5'-CTGTCTGATTCTTGGGTGGTG-3'), Nia1-3 (5'-GTTTCCAGTACGAATGA TAAT-3', 5'-GTGATCTAGTGTGCAAACTTG-3'), Nia1-4 (5'-CAAGTTTGCACACTAGATCAC-3', 5'-ATCTTGACAACCAACTCGAAG-3'), and Nia1-5 (5'-TTGGTGAACTCCTAACTACTG-3', 5'-AAG ACACATGAGCACAATGTT-3'). The genomic DNA of Yunyan 87 was used as the template for PCR amplification. The methylated polymorphic restriction fragments were excised, cloned, and sequenced according to Zhang et al. (2008), and at least five clones were randomly selected for the sequencing of each fragment.

\section{Analysis}

Bands along the same lines as polyacrylamide gels were counted by scale. Monomorphic and polymorphic sites were summed, and the percentage was calculated. Sequences were analyzed using DNAMAN software (version 5.2.2; Lynnon Biosoft) and the GENSCAN Web Server (http://genes.mit.edu/GENSCAN.html). CpG island characteristics were analyzed according to the definition of Gardiner and Frommer (1987): GC content $\geq 30 \%$, observed CpG/expected CpG $\geq$ $0.60, \mathrm{CpG}$ island length $\geq 50 \mathrm{bp}$, and $\mathrm{CpG}$ distance $\geq 100 \mathrm{bp}$.

\section{RESULTS AND DISCUSSION}

\section{Test of DNA integrity and detection of AFLP and MSAP pre-amplification effects}

Gel electrophoresis of genomic DNA ( $0.5 \%$ agarose) showed that only one bright band was near the sample loading slot, indicating that the isolated DNA was not sheared and was suitable for restriction fragment-based fingerprinting.

The agarose gel electrophoresis map of the AFLP and MSAP pre-amplified products (Figure 1) shows that the smear dispersed between 100 and $750 \mathrm{bp}$. Therefore, the well-distributed and continuous fragments met the requirements for selective amplification.

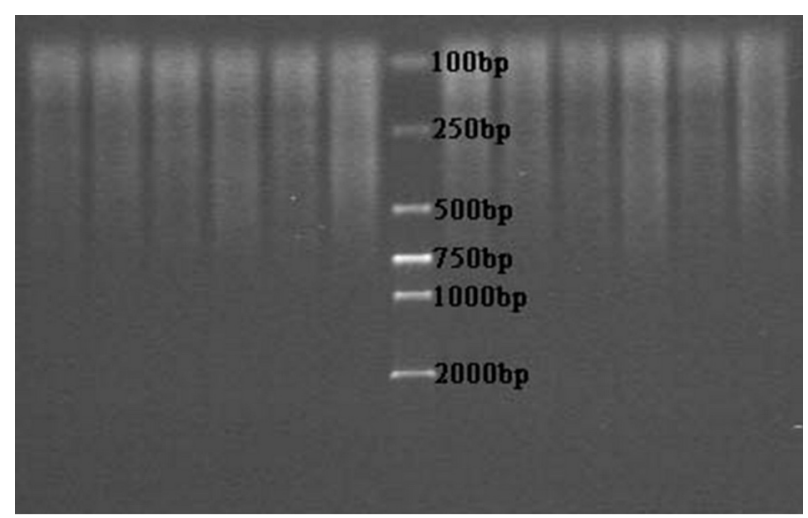

Figure 1. Agarose gel electrophoresis map of pre-amplified products.1-6 represent pre-amplification products; 100-2000 bp represents the size of the DNA marker ladder; A indicates the pre-amplification map for methylation-sensitive amplified polymorphism (MSAP), and B indicates the pre-amplification map for amplified fragment length polymorphism (AFLP). 


\section{AFLP and MSAP analysis}

AFLP has been used previously to analyze the relationships between tobacco germplasm resources (Marché et al., 2001; Julio et al., 2006; Zhang et al., 2008). The mapping and tagging of the underlying genes using AFLP and MSAP markers in plant genomes has mainly been limited to stress tolerance (Labra et al., 2002; Lu et al., 2007; Orellana et al., 2010), and few studies have investigated the relationship between yield, quality, and epigenetic modifications. Eleven different AFLP-selective primer combinations were used in this study, and 335 bands were obtained. Analysis of the AFLP fingerprints of the NC89, K326, Yunyan 85, and Yunyan 87 plants grown in Ya'an, and the two Yunyan 87 plants grown in Yaojia and Xingwen indicated the absence of polymorphic sites for non-methyl-sensitive restriction enzymes (Figure 2). The AFLP profiles indicated a paucity of polymorphisms at the primary sequence level. Two categories were observed in the polyacrylamide electrophoresis gel patterns: 1) Monomorphic loci: the appearance of identical bands; 2) Polymorphic loci: presence-absence polymorphism (dominant markers). The same 11 AFLP primer combinations were used to amplify Yunyan 87 plants collected in 2009 and 2010 (each sample had three repeats), and 242 sites were legible and produced reproducible bands (Table 2); only one monomorphic locus was detected in these sites (Figure 3). The difference between the Yunyan 87 plants collected in 2009 and 2010 was only $0.39 \%$ (34.71\% [84] for 2009 and $35.10 \%$ [85] for 2010), whereas the highest difference in the number of monomorphic sites between Yunyan 87 plants in different areas was 8.26\% (12.40\% [30] for Guangyuan and 20.66\% [50] for Luzhou).

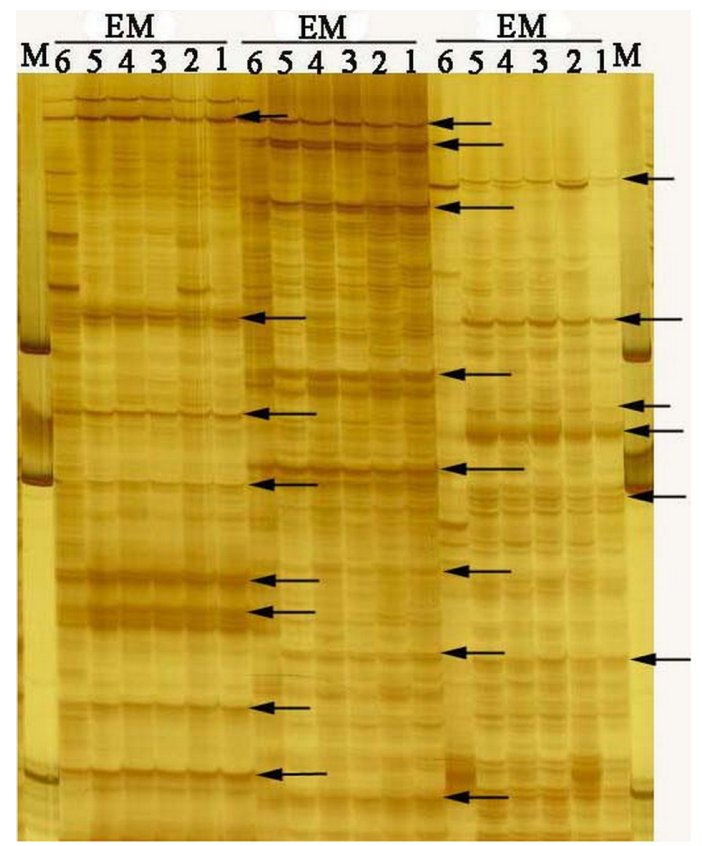

Figure 2. Polyacrylamide gel electrophoresis map of amplified fragment length polymorphism (AFLP) products from samples collected in 2009.1-6 represent amplification products for NC89, K326, Yunyan85, Yunyan 87 (Ya'an), Yunyan 87 (Xingwen), and Yunyan 87 (Yaojia), respectively; the black arrow indicates AFLP monomorphic sites; M represents the DNA marker; EM denotes EcoRI + Msel restriction enzyme digestion production. 
Table 2. Number of bands amplified using 11 amplified fragment length polymorphism (AFLP) selective primer combinations in tobacco cultivars.

\begin{tabular}{|c|c|c|c|c|c|c|}
\hline Samples & GY(09) & GY(10) & $L Z(09)$ & $L Z(10)$ & YB(09) & $\mathrm{YB}(10)$ \\
\hline Monomorphism & 151 & 118 & 180 & 117 & 194 & 105 \\
\hline Percentage & $62.40 \%$ & $48.76 \%$ & $74.38 \%$ & $48.35 \%$ & $80.17 \%$ & $43.39 \%$ \\
\hline Samples & $G Y(09)+L Z(09)+Y B(09)$ & $G Y(10)+L Z(10)+Y B(10)$ & $G Y(09)+G Y(10)$ & $L Z(09)+L Z(10)$ & $Y B(09)+Y B(10)$ & \\
\hline Monomorphism & 84 & 85 & 30 & 50 & 38 & \\
\hline Percentage & $34.71 \%$ & $35.10 \%$ & $12.40 \%$ & $20.66 \%$ & $15.70 \%$ & \\
\hline
\end{tabular}

GY(09) indicates Yunyan 87 cultivars collected in Guangyun, SiChuan, China in 2009; GY(10) indicates Yunyan 87 plants collected in Guangyun, SiChuan, China in 2010.

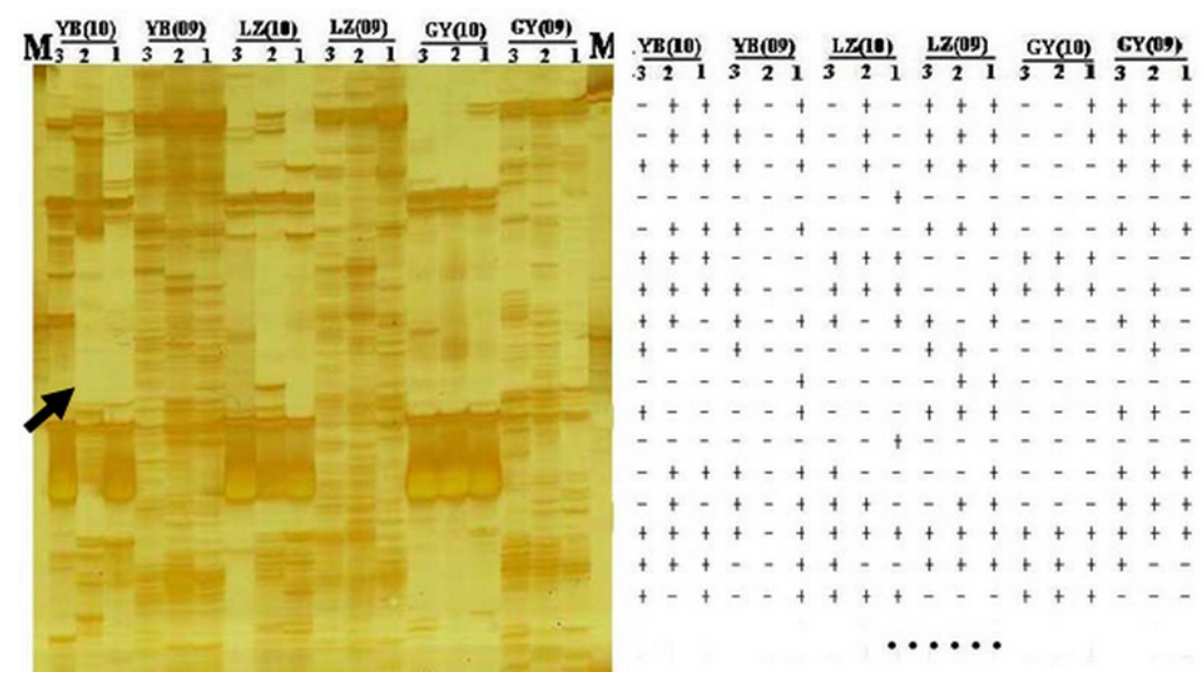

Figure 3. Electrophoresis map ofamplified fragment length polymorphism (AFLP) products and band statistics for Yunyan 87 collected from different areas in 2009 and 2010. 1, 2, and 3 represent three repeated samples of GY(09), $\mathrm{GY}(10), \mathrm{LZ}(09), \mathrm{LZ}(10), \mathrm{YB}(09)$, and $\mathrm{YB}(10)$; - indicates the absence of bands; + indicates the presence of bands; $M$ indicates a DNA marker; the black arrow indicates AFLP monomorphic sites; the primer combinations were E-AAC + Msel-CTC (EcoRI with a selective base pair of AAC and Msel with CTC), E-ACA + Msel-CTG (EcoRI with ACA and Msel with CTG), and E-ACA + Msel-CTC (ECORI with ACA and Msel with CTC); the Figure is part of the polyacrylamide gel electrophoresis map of the 2009 samples.

In this study, two isoschizomers (Hpall and Mspl) that recognize the target site (CCGG) with different methylation sensitivities in eukaryotes were used to generate the MSAP. Hpall can digest both non-methylated CCGG and the hemi-methylated mCCGG motif, whereas Mspl can cleave hemi- or fully methylated CmCGG and $\mathrm{mCmCGG}$ sequences, and non-methylated CCGG. In this study, two categories were analyzed, according to their polyacrylamide electrophoresis gel patterns: 1) Monomorphic loci: CCGG/GGCC methylation patterns were consistent between samples; 2) Polymorphic loci: CCGG/GGCC methylation patterns were different between samples. The eight selective primer combinations used for the parallel digests of EcoRI + Hpall and EcoRI + Mspl produced 251 reproducible amplicons. Of these, only one monomorphic locus was detected (Figure 4). A total of $81(32.27 \%), 90(35.86 \%), 97(38.65 \%)$, and $90(35.86 \%)$ methylated sites were detected in NC89, K326, Yunyan 85, and Yunyan 87, respectively, which were planted in Ya'an, whereas 90 (35.86\%), 108 (43.03\%), and 79 (31.47\%) were detected in Yunyan 87 planted 
in Ya'an, Yaojia, and Xingwen, respectively (Table 2). The MSAP analysis showed that the amount of methylation in different tobacco cultivars planted in the same area was almost identical (32.27, $35.86,38.65$, and $35.86 \%$ ), whereas the amount of methylation in similar tobacco cultivars planted in different areas varied from 31.47 to $43.03 \%$. These data suggest that methylation levels were influenced by regional factors. Therefore, both the AFLP and MSAP results indicate that geographical location affects fingerprint polymorphisms in the tobacco genome.

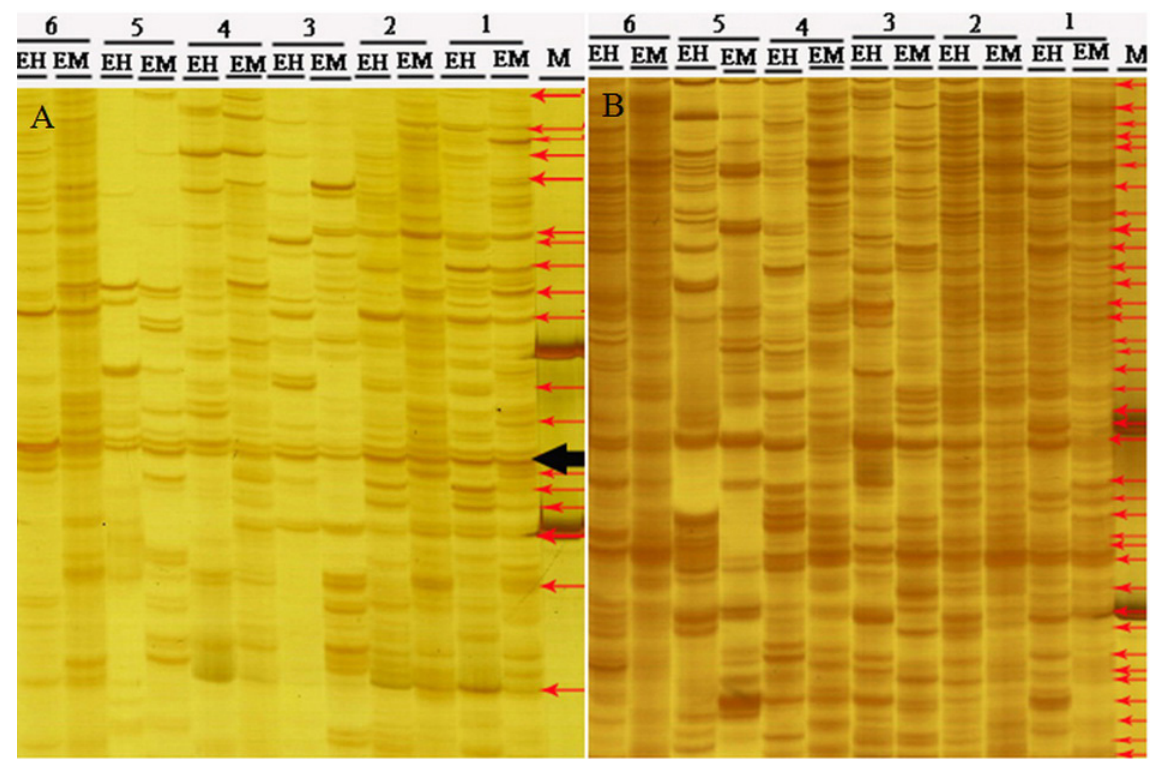

Figure 4. Schematic diagram of methylation patterns in tobacco. A indicates the amplification products of the primer combination E-AAG+ H/M-TCAA, B indicates the amplification products of the primer combination E-AAC+H/M-TCTA; the black arrow indicates the methylation monomorphic site, and the red arrows indicate methylation polymorphic sites;1-6 represent NC89, K326, Yunyan 85, Yunyan 87 (Ya'an), Yunyan 87 (Xingwen), and Yunyan 87 (Yaojia), respectively; some sites were methylation monomorphicin 1 and 2, some sites were methylation monomorphicin 5 and 6 , some sites were methylation monomorphicin 4 and 5 , and other sites were methylation monomorphicin 4 and 6; $\mathrm{M}$ indicates the DNA marker; $\mathrm{EH}$ indicates $\mathrm{EcoRI}+$ Hpall restriction enzyme digestion production, and EM indicates $E c o R I+M s p l$ restriction enzyme digestion production.

\section{Sequence characterization of methylated polymorphic restriction fragments}

Forty-one polymorphic methylated fragments were successfully isolated and sequenced, and the results of a BLAST analysis showed that homologous sequences were found for 35 bands. Nucleotide BLAST searches showed that 3 of the 35 sequences were $90 \%$ similar to Nia1 nucleotides (GenBank accession No. X14058).

Cytosine methylation is a common form of DNA modification that plays a role in the silencing of transposons and repeats in the genomes of vertebrates, plants, and fungi (Zilberman et al., 2007). In the genomes of higher plants, approximately 20 to $50 \%$ of methylation sites are located in cytosine residues, and $90 \%$ of methylated sites are located in CpG or CpNpG (Chan et al., 2005). In the current study, 25 typical CpG islands were isolated from 41 methylation fragments, and the highest values of the GC content, the observed $\mathrm{CpG}$ /expected $\mathrm{CpG}$ ratio, and $\mathrm{CpG}$ island 
length were 53.89\%, 1.52, and $195 \mathrm{bp}$, respectively (Table 3). The results show that CpG islands are abundant in methylated gene fragments. The sequence alignments of the NR gene in Yunyan 87 cultivars collected from different regions also showed that C-T changes occurred in CG-rich regions. Results from the current and previous studies suggest that $\mathrm{CpG}$ dinucleotide clusterenriched areas of the genome are possible sites of DNA cytosine methylation.

\begin{tabular}{|c|c|c|c|c|c|c|c|}
\hline Primer & & Length (bp) & Start (bp) & End (bp) & GC content $(\%)$ & $\begin{array}{l}\text { Observed } \mathrm{CpG} / \\
\text { expected } \mathrm{CpG}\end{array}$ & $\begin{array}{l}\text { CpG island } \\
\text { length (bp) }\end{array}$ \\
\hline \multirow[t]{5}{*}{ EcoRI-ACA } & \multirow[t]{5}{*}{ Hpall/Mspl-TCAA } & 278 & 47 & 233 & 48.59 & 1.07 & 177 \\
\hline & & 294 & 47 & 239 & 53.89 & 1.07 & 193 \\
\hline & & 278 & 47 & 233 & 49.15 & 1.05 & 177 \\
\hline & & 204 & 97 & 147 & 43.14 & 0.43 & 51 \\
\hline & & 204 & 62 & 149 & 48.86 & 0.76 & 88 \\
\hline \multirow[t]{6}{*}{ EcoRI-AAC } & \multirow[t]{6}{*}{ Hpall/Mspl-TCTA } & 217 & 47 & 108 & 53.23 & 0.74 & 62 \\
\hline & & 216 & 47 & 157 & 47.75 & 0.95 & 111 \\
\hline & & 215 & 47 & 160 & 50.88 & 1.09 & 114 \\
\hline & & 239 & 48 & 184 & 49.64 & 0.91 & 137 \\
\hline & & 230 & 77 & 174 & 30.61 & 0.89 & 98 \\
\hline & & 201 & 47 & 144 & 42.86 & 0.91 & 98 \\
\hline \multirow[t]{3}{*}{ EcoRI-ACA } & \multirow[t]{3}{*}{ Hpall/Mspl-TCAA } & 277 & 47 & 222 & 50.00 & 1.12 & 176 \\
\hline & & 277 & 47 & 222 & 48.86 & 1.16 & 176 \\
\hline & & 250 & 70 & 193 & 36.29 & 1.04 & 124 \\
\hline \multirow[t]{7}{*}{ EcoRI-AAC } & \multirow[t]{7}{*}{ Hpall/Mspl-TCTA } & 236 & 47 & 180 & 40.30 & 1.11 & 134 \\
\hline & & 257 & 50 & 200 & 37.09 & 1.03 & 151 \\
\hline & & 206 & 96 & 150 & 27.27 & 0.98 & 55 \\
\hline & & 186 & 49 & 129 & 28.40 & 0.61 & 81 \\
\hline & & 162 & 49 & 105 & 35.09 & 1.52 & 57 \\
\hline & & 276 & 47 & 221 & 48.57 & 1.08 & 175 \\
\hline & & 283 & 47 & 221 & 43.09 & 1.20 & 181 \\
\hline EcoRI-AAC & Hpall/Mspl-TCTT & 230 & 49 & 125 & 25.97 & 0.92 & 77 \\
\hline EcoRI-AAG & Hpall/Mspl-TCAA & 296 & 48 & 242 & 47.18 & 1.11 & 195 \\
\hline
\end{tabular}

\section{Sequence analysis of NR genes in Yunyan 87 cultivars from different regions}

Because of deamination, the 5'-ending methylation of cytosine may result in thymine and a C-T transition mutation (Hepburn et al., 1987). Unlike a cytosine to uracil mutation that is efficiently repaired, a cytosine to thymine mutation can be corrected only by mismatch system repair, which is very inefficient. The conversion from a methylated CG sequence to a TG sequence could lead to a deficiency of the CG sequence in active genes. The biological function of DNA methylation may be related to gene silencing (Paszkowski and Whitham, 2001). Previous studies have reported that DNA methylation may regulate gene expression in various ways (Severin et al., 2011). C-T changes appeared in the NR gene sequences of Yunyan 87 plants grown in Ya'an, Yaojia, and Xingwen. The changes were concentrated in CG- and CCGG-rich regions (Figure 5 and Table 4), suggesting that these variations (that mainly occurred in $\mathrm{CpG}$ island-enriched areas) might alter gene structures. Cell characteristics are also affected by constituent proteins, which result from specific patterns of gene expression (Bird, 2002); numerous plant proteins are related to a plant's characteristics. These data suggest that variations in cytosine methylation patterns may result in different tobacco characteristics. The sequence alignment of the NR gene also indicated that different methylated patterns might exist in the same Yunyan 87 cultivars planted in different regions. Therefore, we hypothesize that variations in tobacco quality are influenced by geographical factors. 


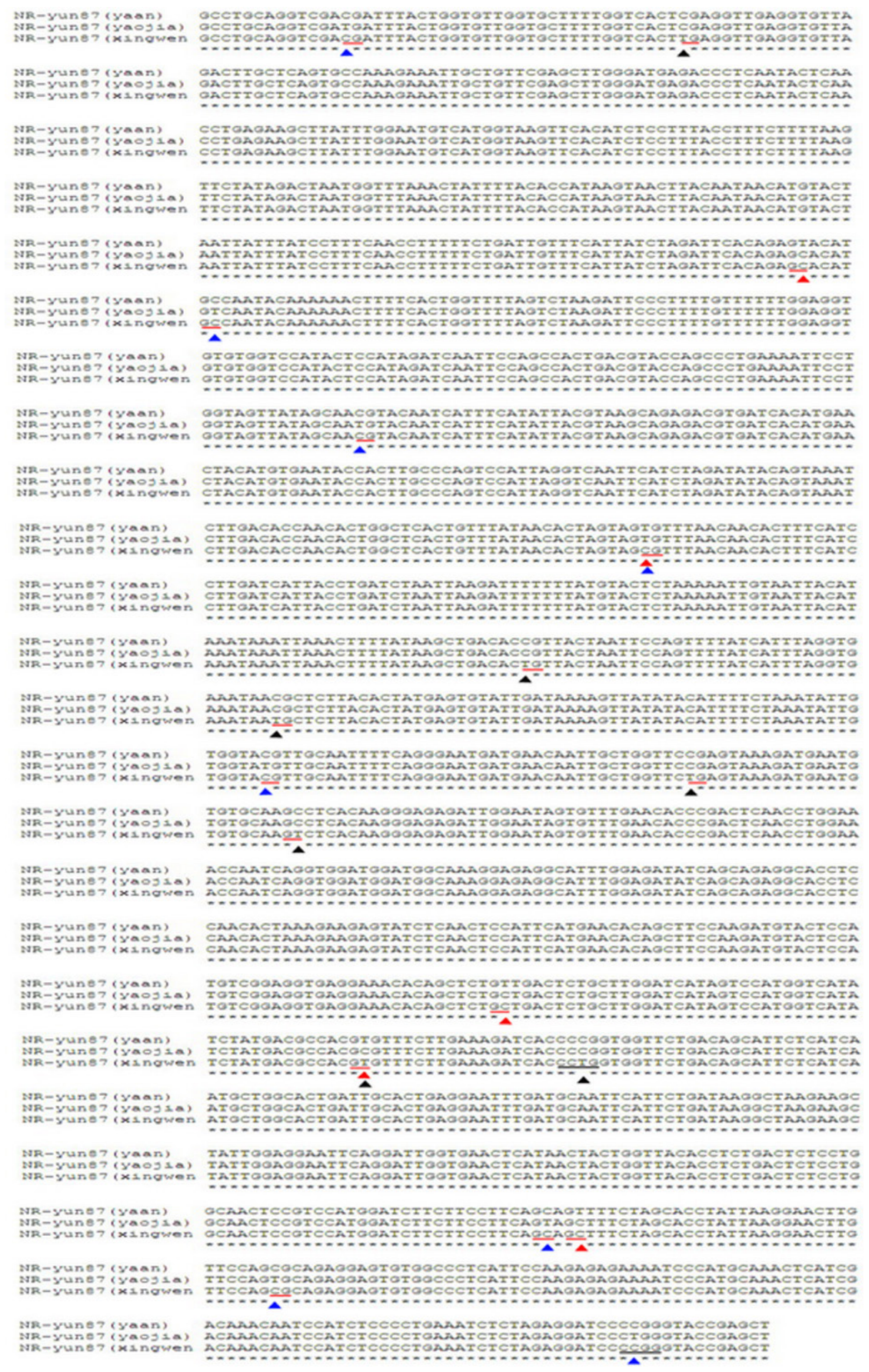

Figure 5. Sequence alignment of the NR gene in the Yunyan87 cultivar from different regions. Red, blue, and black triangles indicate $\mathrm{C}$ - $\mathrm{T}$ changes in the gene sequence of the Yunyan 87 cultivar taken from Ya'an, Yaojia, and Xingwen, respectively. Red lines indicate CG- or GC-rich regions, black lines indicate CCGG-rich regions. 
Table 4. Number of bands amplified using eight methylation-sensitive amplified polymorphism (MSAP) selective primer combinations in tobacco cultivars.

\begin{tabular}{|c|c|c|c|c|c|c|c|c|c|c|c|c|c|}
\hline \multirow[t]{3}{*}{ Primer combination } & \multirow[t]{3}{*}{ Amplification site } & \multicolumn{2}{|c|}{ NC89 } & \multicolumn{2}{|c|}{ K326 } & \multicolumn{2}{|c|}{ yunyan85 } & \multicolumn{2}{|c|}{$\begin{array}{c}\text { yunyan } 87 \\
\text { (Ya'an) }\end{array}$} & \multicolumn{2}{|c|}{$\begin{array}{l}\text { yunyan } 87 \\
\text { (Xingwen) }\end{array}$} & \multicolumn{2}{|c|}{$\begin{array}{c}\text { yunyan } 87 \\
\text { (Yaojia) }\end{array}$} \\
\hline & & \multicolumn{2}{|c|}{ Methylated site } & \multicolumn{2}{|c|}{ Methylated site } & \multicolumn{2}{|c|}{ Methylated site } & \multicolumn{2}{|c|}{ Methylated site } & \multicolumn{2}{|c|}{$\overline{\text { Methylated site }}$} & \multicolumn{2}{|c|}{ Methylated site } \\
\hline & & Full & Hemi & Full & Hemi & Full & Hemi & Full & Hemi & Full & Hemi & Full & Hemi \\
\hline EcoRI-ACA + Hpall/Mspl-TCAA & 26 & 4 & 4 & 9 & 0 & 8 & 3 & 1 & 2 & 6 & 8 & 6 & 1 \\
\hline EcoRI-AAC + Hpall/Mspl-TCTC & 23 & 3 & 4 & 5 & 5 & 7 & 4 & 5 & 1 & 3 & 7 & 1 & 4 \\
\hline EcoRI-AAC + Hpall/Mspl-TCTT & 30 & 10 & 0 & 4 & 4 & 6 & 5 & 6 & 7 & 4 & 2 & 10 & 0 \\
\hline EcoRI-AAC + Hpall/Mspl-TCTA & 25 & 5 & 8 & 3 & 9 & 9 & 0 & 1 & 7 & 6 & 5 & 8 & 1 \\
\hline EcoRI-AAC + Hpall/Mspl-TCTG & 44 & 8 & 9 & 7 & 5 & 6 & 11 & 10 & 14 & 18 & 8 & 19 & 4 \\
\hline EcoRI-AAG + Hpall/Mspl-TCAA & 48 & 6 & 4 & 5 & 10 & 8 & 12 & 10 & 9 & 13 & 10 & 11 & 3 \\
\hline EcoRI-ACA + Hpall/Mspl-TCTA & 25 & 4 & 4 & 6 & 4 & 5 & 5 & 4 & 2 & 2 & 4 & 0 & 4 \\
\hline EcoRI-AAG + Hpall/Mspl-TCTA & 30 & 6 & 2 & 8 & 6 & 1 & 2 & 5 & 6 & 6 & 6 & 2 & 5 \\
\hline \multirow[t]{2}{*}{ Total } & 251 & 46 & 35 & 47 & 43 & 50 & 42 & 42 & 48 & 58 & 50 & 57 & 22 \\
\hline & & 81 & & 90 & & 97 & & 90 & & 108 & & 79 & \\
\hline \multirow[t]{2}{*}{ Rate of methylated site (\%) } & & 18.32 & 13.91 & 18.72 & 17.13 & 19.92 & 16.73 & 16.73 & 19.12 & 23.10 & 19.92 & 22.71 & 8.76 \\
\hline & & 32.27 & & 35.86 & & 38.65 & & 35.86 & & 43.03 & & 31.47 & \\
\hline
\end{tabular}

In summary, different geographical factors could affect AFLP fingerprints, and variations in methylation patterns, in the tobacco genome. Different methylation patterns could influence the expression of quality-related genes through T-C C-T nucleotide replacement, resulting in the different characteristics of different tobacco cultivars. These results indicate that $\mathrm{C}-\mathrm{T}$ nucleotide replacement might be responsible for the tobacco phenotype, and this expression may be affected by geographical factors. Therefore, the results of the current study suggest that molecular markers could be used to analyze polymorphisms that are affected by geographical factors, which lead to variations in cytosine-methylated patterns. In addition, tobacco assessment indices could be optimized, and the quality of tobacco improved.

\section{REFERENCES}

Bahulikar RA, Stanculescu D, Preston CA and Baldwin IT (2004). ISSR and AFLP analysis of the temporal and spatial population structure of the post-fire annual, Nicotiana attenuata, in SW Utah. BMC Ecol. 4: 12.

Baurens FC, Bonnot F, Bienvenu D, Causse S, et al. (2003). Using SD-AFLP and MSAP to assess CCGG methylation in the banana genome. Plant Mol. Biol. Rep. 21: 339-348.

Bird A (2002). DNA methylation patterns and epigenetic memory. Genes Dev. 16: 6-21.

Chan SW, Henderson IR and Jacobsen SE (2005). Gardening the genome: DNA methylation Arabidopsis thaliana. Nat. Rev. Genet. 6: 351-360.

Chandel G, Datta K and Datta SK (2010). Detection of genomic changes in transgenic Bt rice populations through genetic fingerprinting using amplified fragment length polymorphism (AFLP). GM Crops 1: 327-336.

Falke KC, Susić Z, Hackauf B, Korzun V, et al. (2008). Establishment of introgression libraries in hybrid rye (Secale cereale L.) from an Iranian primitive accession as a new tool for rye breeding and genomics. Theor. Appl. Genet. 117: 641-652.

Frascaroli E, Schrag TA and Melchinger AE (2013). Genetic diversity analysis of elite European maize (Zea mays L.) inbred lines using AFLP, SSR, and SNP markers reveals ascertainment bias for a subset of SNPs. Theor. Appl. Genet. 126: 133-141.

Gardiner GM and Frommer M (1987). CpG islands in vertebrate genomes. J. Mol. Biol. 196: 261-282.

Guimil S and Dunand C (2006). Patterning of Arabidopsis epidermal cells: epigenetic factors regulate the complex epidermal cell fate pathway. Trends Plant Sci. 11: 601-609.

Henderson IR and Jacobsen SE (2007). Epigenetic inheritance in plants. Nature 447: 418-424.

Hepburn AG, Belanger FC and Mattheis JR (1987). DNA methylation in plants. Genesis 8: 475-493.

Jiang H, Liao B, Ren X, Lei Y, et al. (2007). Comparative assessment of genetic diversity of peanut (Arachis hypogaea L.) genotypes with various levels of resistance to bacterial wilt through SSR and AFLP analyses. J. Genet. Genomics 34 : 544-554. 
Julio E, Verrier JL and de Borne Dorlhac F (2006). Development of SCAR markers linked to three disease resistances based on AFLP within Nicotiana tabacum L. Theor Appl. Genet. 112: 335-346.

Labra M, Ghiani A, Citterio S, Sgorbati S, et al. (2002). Analysis of cytosine methylation pattern in response to water deficit in pea root tips. Plant Biol. 4: 694-699.

Li XL, Yu XM, Wang N, Feng QZ, et al. (2007). Genetic and epigenetic instabilities induced by tissue culture in wild barley (Hordeum brevisubulatum (Trin.) Link). Plant Cell Tiss. Organ Cult. 90: 153-168.

Lu Y, Rong T and Cao M (2008). Analysis of DNA methylation in different maize tissues. J. Genet. Genomics 35: 41-48.

Lu GY, Wu XM, Chen BY, Gao GZ, et al. (2007). Evaluation of genetic and epigenetic modification in rapeseed (Brassica napus) induced by salt stress. J. Integr. Plant Biol. 49: 1599-1607.

Marché L, Valette S, Grenier E and Mugniéry D (2001). Intra-species DNA polymorphism in the tobacco cyst-nematode complex (Globodera tabacum) using AFLP. Genome 44: 941-946.

Mason G, Noris E, Lanteri S, Acquadro A, et al. (2008). Potentiality of methylation-sensitive amplification polymorphism (MSAP) in identifying genes involved in Tomato response to Tomato yellow leaf curl Sardinia virus. Plant Mol. Biol. Rep. 26: 156-173.

Noyer JL, Causse S, Tomekpe K, Bouet A, et al. (2005). A new image of plantain diversity assessed by SSR, AFLP and MSAP markers. Genetica 124: 61-69.

Orellana S, Yañez M, Espinoza A, Verdugo I, et al. (2010). The transcription factor SIAREB1 confers drought, salt stress tolerance and regulates biotic and abiotic stress-related genes in tomato. Plant Cell Environ. 33: 2191-2208.

Paszkowski J and Whitham SA (2001). Gene silencing and DNA methylation processes. Curr. Opin. Plant Biol. 4: $123-129$.

Portis E, Acquadro A, Comino C and Lanteri S (2004). Analysis of DNA methylation during germination of pepper (Capsicum annuum L.) seeds using methylation-sensitive amplification polymorphism (MSAP). Plant Sci. 166: 169-178.

Reyna-López GE, Simpson J and Ruiz-Herrera J (1997). Differences in DNA methylation patterns are detectable during the dimorphic transition of fungi by amplification of restriction polymorphisms. Mol. Gen. Genet. 253: 703-710.

Severin PM, Zou X, Gaub HE and Schulten K (2011). Cytosine methylation alters DNA mechanical properties. Nucl. Acids Res. 39: 8740-8751.

Sha AH, Lin XH, Huang JB and Zhang DP (2005). Analysis of DNA methylation related to rice adult plant resistance to bacterial blight based on methylation-sensitive AFLP (MSAP) analysis. Mol. Genet. Genomics 273: 484-490.

Shan XH, Li YD, Liu XM, Wu Y, et al. (2012). Comparative analyses of genetic/epigenetic diversities and structures in a wild barley species (Hordeum brevisubulatum) using MSAP, SSAP and AFLP. Genet. Mol. Res. 11: 2749-2759.

Tang ZX, Fu SL, Ren ZL, Zhou JP, et al. (2008). Variation of tandem repeat, regulatory element, and promoter regions revealed by wheat-rye amphiploids. Genome 51: 399-408.

Vos P, Hogers R, Bleeker M, Reijans M, et al. (1995). AFLP: a new technique for DNA fingerprinting. Nucl. Acids Res. 23: 4407-4414.

Xiong LZ, Xu CG, Saghai Maroof MA and Zhang Q (1999). Patterns of cytosine methylation in an elite rice hybrid and its parental lines, detected by a methylation-sensitive amplification polymorphism technique. Mol. Gen. Genet. 261: $439-446$.

Zhang HY, Liu XZ, He CS and Yang YM (2008). Genetic diversity among flue-cured tobacco cultivars based on RAPD and AFLP markers. Braz. Arch. Biol. Technol. 51: 1097-1101.

Zhang Y, Liu ZH, Liu C, Yang ZJ, et al. (2008). Analysis of DNA methylation variation in wheat genetic background after alien chromatin introduction based on methylation-sensitive amplification polymorphism. Chin. Sci. Bull. 53: 58-69.

Zhang J, Lu Y and Yu S (2005). Cleaved AFLP (cAFLP), a modified amplified fragment length polymorphism analysis for cotton. Theor. Appl. Genet. 111: 1385-1395.

Zhao X, Chai Y and Liu B (2007). Epigenetic inheritance and variation of DNA methylation level and pattern in maize intraspecific hybrids. Plant Sci. 172: 930-938.

Zilberman D, Gehring M, Tran RK, Ballinger T, et al. (2007). Genome-wide analysis of Arabidopsis thaliana DNA methylation uncovers an interdependence between methylation and transcription. Nat. Genet. 39: 61-69. 